\title{
D1/D5 receptors and histone deacetylation mediate the Gateway Effect of LTP in hippocampal dentate gyrus
}

\author{
Yan-You Huang, ${ }^{1,3,9}$ Amir Levine, ${ }^{2,3,8}$ Denise B. Kandel, ${ }^{2,3,4}$ Deqi Yin, ${ }^{6}$ Luca Colnaghi, ${ }^{1,6}$ \\ Bettina Drisaldi, ${ }^{1,7}$ and Eric R. Kandel ${ }^{1,2,3,5,6,9}$ \\ ${ }^{1}$ Department of Neuroscience, ${ }^{2}$ Department of Psychiatry, College of Physicians and Surgeons of Columbia University, New York, \\ New York 10032, USA; ${ }^{3}$ New York State Psychiatric Institute, New York, New York 10032, USA; ${ }^{4}$ Mailman School of Public \\ Health, Columbia University, New York, New York 10032, USA; ${ }^{5}$ Kavli Institute for Brain Science, College of Physicians and \\ Surgeons of Columbia University, New York, New York 10032, USA; ${ }^{6}$ Howard Hughes Medical Institute, College of Physicians \\ and Surgeons of Columbia University, New York, New York 10032, USA; ${ }^{7}$ Italian Academy for Advanced Studies at Columbia \\ University, New York, New York 10022, USA; ${ }^{8}$ Center for Addiction and Mental Health, Toronto, Ontario, M5T 1R8, Canada
}

The dentate gyrus (DG) of the hippocampus is critical for spatial memory and is also thought to be involved in the formation of drug-related associative memory. Here, we attempt to test an aspect of the Gateway Hypothesis, by studying the effect of consecutive exposure to nicotine and cocaine on long-term synaptic potentiation (LTP) in the DG. We find that a single injection of cocaine does not alter LTP. However, pretreatment with nicotine followed by a single injection of cocaine causes a substantial enhancement of LTP. This priming effect of nicotine is unidirectional: There is no enhancement of LTP if cocaine is administrated prior to nicotine. The facilitation induced by nicotine and cocaine can be blocked by oral administration of the dopamine D1/D5 receptor antagonist (SKF 83566) and enhanced by the D1/D5 agonist (SKF 38393). Application of the histone deacetylation inhibitor suberoylanilide hydroxamic acid (SAHA) simulates the priming effect of nicotine on cocaine. By contrast, the priming effect of nicotine on cocaine is blocked in genetically modified mice that are haploinsufficient for the CREB-binding protein (CBP) and possess only one functional CBP allele and therefore exhibit a reduction in histone acetylation. These results demonstrate that the DG of the hippocampus is an important brain region contributing to the priming effect of nicotine on cocaine. Moreover, both activation of dopamine-D1 receptor/ PKA signaling pathway and histone deacetylation/CBP mediated transcription are required for the nicotine priming effect in the DG.

In human populations, there is a well-defined sequence of involvement in drugs of abuse, in which the use of nicotine or alcohol precedes the use of marijuana, which, in turn, precedes the use of cocaine. This developmental sequence of drug involvement has been referred to as the Gateway Effect or Gateway Hypothesis (Kandel 1975, 2002; Yamaguchi 1984). Nicotine is one of the most commonly used drugs of abuse. Prior studies have demonstrated that nicotine not only produces addictive effects by itself, but also sensitizes reward pathways for the addictive effects of other psychostimulants. Thus, nicotine can serve as a "gateway" drug that may lead to a change in the rewarding effect of other drugs, such as cocaine. Behavioral studies in rodents indicated that prior exposure to nicotine produces a greater increase in selfadministration, sensitization, and conditioned place preference than the administration of cocaine alone (Klein 2001; Desai and Terry 2003; Collins et al. 2004; McMillen et al. 2005; McQuown et al. 2009; Levine et al. 2011; Mello and Newman 2011). However, the molecular and synaptic mechanisms underlying this gateway effect are not completely understood. Our laboratory has previously documented that the Gateway Effect not only influences behavior but also alters synaptic plasticity in certain brain regions. For instance, prior exposure to nicotine enhances the ability of cocaine to depress LTP in the nucleus accumbens (Levine

\footnotetext{
${ }^{9}$ Corresponding authors E-mail erk5@columbia.edu E-mail yyh3@columbia.edu

Article is online at http://www.learnmem.org/cgi/doi/10.1101/Im.032292.113. Freely available online through the Learning \& Memory Open Access option.
}

et al. 2011) and enhances LTP in the amygdala (Huang et al. 2013). This raised the question: Is the priming effect of nicotine on cocaine also evident in the hippocampus, which is critical for spatial memory and other forms of explicit memory concerned with people and objects? Here we focus on the priming effect of nicotine on subsequent cocaine administration in the dentate gyrus (DG) of the hippocampus.

The dentate gyrus of the hippocampus plays a vital role in spatial memory, and is also related to drug associated memory. The administration of cocaine or nicotine modifies spatial memory and synaptic plasticity in the DG (Scerri et al. 2006; Kenney and Gould 2008; Perez et al. 2010; Fole et al. 2011; Iniguez et al. 2012). Lesion of the DG blocks cocaine-induced conditioned place preference (CPP) (Meyers et al. 2006; Hernandez-Rabaza et al. 2008). Moreover, the DG is one of the few regions in the adult brain where neurogenesis continues to take place (Christie and Cameron 2006; Aimons et al. 2010) and neurogenesis is thought to play an important role in the formation of addictive memory (Eisch and Harburg 2006; Canales 2007, 2010; Noona et al. 2010). Finally, the DG is a brain region that is highly sensitive to nicotine and significantly affects synaptic plasticity. Either application of nicotine in brain slices or subcutaneous injection of nicotine, in vivo, enhances LTP in dentate gyrus (Sawada et al. 1994; Curran and Connor 2003; Welsby et al.

(C) 2014 Huang et al. This article, published in Learning \& Memory, is available under a Creative Commons License (Attribution-NonCommercial 3.0 Unported), as described at http://creativecommons.org/licenses/by-nc/3.0/. 
2006, 2009). Acute nicotine treatment prevents sleep deprivation-induced impairment of LTP in the DG (Aleisa et al. 2011) and administration of a highdose of nicotine causes synaptic potentiation in the DG, without pairing of tetanic stimulation (Matsuyama et al. 2000; Tang and Dani 2009). These studies in the DG have, however, focused on the effects of nicotine alone.

We were interested in knowing, would nicotine also play an important role in priming the DG for the effects of other drugs of abuse, such as cocaine? In our previous studies, we established a mouse model for the sequential use of oral administration of nicotine $(10 \mathrm{mg} /$ L) followed by an injection of cocaine $(30 \mathrm{mg} / \mathrm{kg})$. We found that the administration of nicotine followed by cocaine altered cocaine-induced changes in synaptic plasticity in the nucleus accumbens and the amygdala (Levine et al. 2011; Huang et al. 2013). We now used this paradigm to examine synaptic plasticity in the DG. We address the following four questions:

1. What are the effects of 7-d oral administration of a low dose of nicotine on LTP in the DG by itself and when the administration of nicotine is followed by an injection of cocaine (priming effect)?

2. Since the central dopaminergic system may play an important role in nicotine-mediated synaptic plasticity (Mansvelder and McGehee 2002; Kauer and Malenka 2007; Tang and Dani 2009), we further ask: Do the dopamine D1/D5 receptors play any role in the priming effect of nicotine on cocaine?

3. Since we have earlier found that nicotine enhances histone acetylation in the striatum (Levine et al. 2011), we examine whether the priming effect of nicotine on cocaine in the DG is simulated by an inhibitor of histone deacetylase (HDAC).

4. Finally, the CREB-binding protein CBP is a histone acetyl transferase (HAT). CBP haploinsufficient mice carry only one functional CBP allele and have a reduction in histone acetylation (Levine et al. 2011). We therefore also ask: How does the sequential treatment paradigm of nicotine on cocaine affect LTP in the DG in CBP haploinsufficient mice?

\section{Results}

\section{D1/D5 receptors mediate the priming effect of} nicotine in the DG

Since behavioral studies on the priming effect of nicotine on cocaine in humans and in rodents are all performed with the intact GABAergic-system, we studied LTP in DG hippocampal slices without treatment with a GABA-antagonist. With intact GABAergic inhibition, a single tetanus $(1 \times 100 \mathrm{~Hz})$ induced only a weak
LTP in the DG of control animals (115 $\pm 3 \%, n=10,50$ min after tetanus) (Fig. 1A).

Does nicotine have any priming effect on cocaine-induced changes of LTP in the DG under those circumstances? To address this question we first examined the effects of nicotine alone and cocaine alone. Oral administration of low doses of nicotine (10 $\mu \mathrm{g} / \mathrm{mL}$ ) for $7 \mathrm{~d}$ did not alter the induction of LTP. In mice treated with nicotine for $7 \mathrm{~d}$, LTP was $116 \pm 2 \%(n=8)$, which was not significantly different from controls $(P>0.05)$ (Fig. 1B). Similarly, a single injection of cocaine $(30 \mathrm{mg} / \mathrm{kg})$ did not significantly alter the induction of LTP $(114 \pm 3 \%, n=7)$ (Fig. 1C). However, when 7-d exposure to nicotine was followed by the injection of cocaine, a significant enhancement of LTP emerged. A single tetanus $(1 \times 100 \mathrm{~Hz})$ now produced LTP, which was significantly greater than that obtained when mice received a cocaine injection alone (141 $\pm 6 \%, n=8, P<0.01$ ) (Fig. 1D). The enhancement of LTP 
was not associated with any changes in basal synaptic transmission (input-output curve) (Fig. 1E). We next examined the effect of short-term exposure to nicotine. Mice were pretreated with nicotine for $1 \mathrm{~d}$, followed by the injection of cocaine. Although 7-d nicotine exposure followed by cocaine produced a long-lasting enhancement of LTP, 1-d nicotine exposure followed by cocaine only produced a short-lasting enhancement. In this latter group of mice, LTP was enhanced $10 \mathrm{~min}$ after tetanus (nicotine+ cocaine, $146 \pm 5 \%, n=6$; control, $122 \pm 5 \%, n=6, P<0.05$ ) (Fig. 2B). However, LTP decayed $50 \mathrm{~min}$ after the tetanus, which was different from the stable enhancement of LTP in mice treated with nicotine for $7 \mathrm{~d}$ (Fig. 1D).

Using the protocol of 1-d nicotine exposure, we found that the enhancement of LTP induced by nicotine and cocaine was unidirectional. Reversing the sequence, a single injection of cocaine prior to 1-d nicotine exposure did not produce any significant enhancement of LTP $(121 \pm 6 \%, 10$ min after tetanus, $n=$ $6, P>0.05$ ) (Fig. 2C). Similarly, repeated injection of cocaine for $7 \mathrm{~d}$ followed by 1-d nicotine exposure did not produce any enhancement of LTP in DG either $10 \mathrm{~min}(124 \pm 5 \%)$ or $50 \mathrm{~min}$ $(120 \pm 6 \%)$ after tetanus $(n=6, P>0.05)$ (Fig. 2D).

The central dopaminergic system plays an important role in the effect of nicotine (Mansvelder and McGehee 2002; Kauer and Malenka 2007; Tang and Dani 2009). We therefore asked: Is the priming effect of nicotine on cocaine-induced changes of LTP mediated by the activation of dopamine receptors? Under oral administration, both the D1/D5 agonist SKF 38393 and antagonist SKF 83566 are rapidly absorbed and penetrate the blood-brain barrier. Indeed, the agonist is used clinically for the treatment of Parkinson's disease and nicotine craving (Braun et al. 1987; Nakagome et al. 2011).
A 1-d nicotine

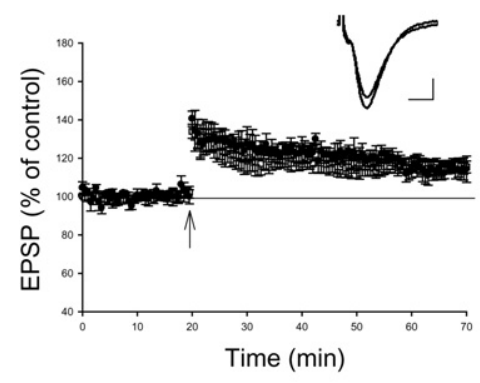

C 1-d cocaine prior to $1-d$ nicotine

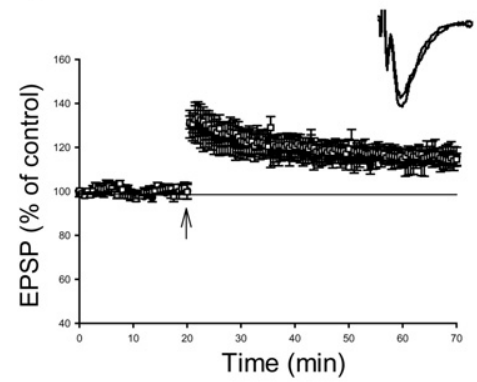

B 1-d nicotine prior to cocaine

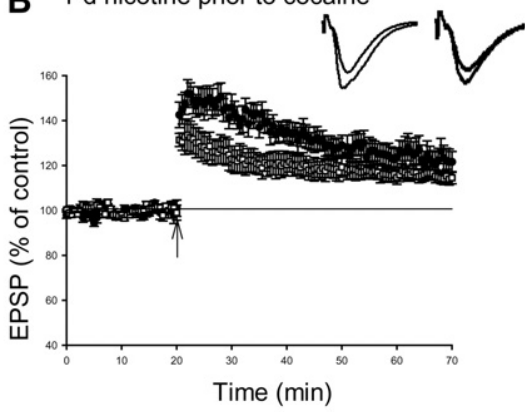

D 7-d cocaine prior to $1-d$ nicotine

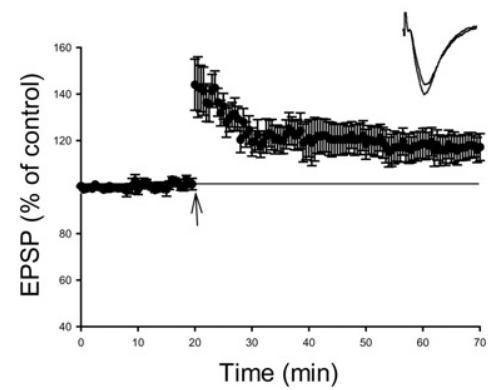

Figure 2. The priming effect of nicotine on cocaine is unidirectional. (A) One-day nicotine exposure did not alter LTP. (Open circles) control, (closed circles) nicotine. (B) One-day nicotine exposure followed by cocaine injection produces a short-lasting enhancement of LTP. (Open squares) cocaine, (closed circles) nicotine + cocaine. (C) Cocaine injection followed by 1-d nicotine exposure (reverse sequence) did not produce any enhancement of LTP. (Open squares) control, (closed circles) nicotine + cocaine. $(D)$ Seven-day cocaine followed by 1-d nicotine did not produce significant enhancement of LTP.
We first applied the D1/D5 receptor antagonist (SKF 83566) into the drinking water together with nicotine for $7 \mathrm{~d}$, followed the injection of cocaine. We found that coadministration of the antagonist SKF $83566(20 \mu \mathrm{g} / \mathrm{mL})$ and nicotine $(10 \mu \mathrm{g} / \mathrm{mL})$ significantly blocked the enhancement of LTP induced by pretreatment with nicotine (SKF 83566+nicotine+cocaine, $120 \pm$ $4 \%, n=12$; nicotine + cocaine, $143 \pm 5 \%, n=6, P<0.01$ ) (Fig. 3A). As a control, SKF 83566 alone did not alter LTP (115 $\pm 6 \%$, $n=5$ ) (Fig. 3B). These results indicate that the priming effect of nicotine on cocaine requires the activation of D1/D5 receptors.

We next asked whether the D1/D5 receptor agonist can enhance the priming effect of nicotine. We now added the D1/D5 agonist SKF $38393(10 \mu \mathrm{g} / \mathrm{mL})$ into the drinking water together with nicotine, followed by the injection of cocaine. The addition of SKF 38393 to nicotine did not produce further enhancement of nicotine +cocaine, $137 \pm 6 \%, n=7, P>0.05$ ) (Fig. 3C). However, was enhanced in mice coadministered SKF 38393 and nico38393 and nicotine for $1 \mathrm{~d}$ prior to the injection of cocaine 38393 treated with nicotine for $1 \mathrm{~d}$ without adding SKF 38393 (nicotine+cocaine, $121 \pm 5 \%, n=6, P<0.01$ ) (Fig. 3D). As a control, oral administration of SKF 38393 alone for $1 \mathrm{~d}$ did not pro0.01 ) (Fig. 3E). These results provide evidence that the priming efof nicotine on cocaine in DG-LTP is at least partly mediated by

Because the activation of the D1/D5 receptors increases cAMP and activates the protein kinase A (PKA) signaling pathway, we examined the effect of a PKA inhibitor on the priming effect of nicotine on cocaine following short- and long-term exposure to nicotine. We applied the PKA inhibitor KT5720 $(2 \mu \mathrm{M})$ to the perfusion bath 20 min before tetanus. This did not alter LTP induced by a single tetanus. However, KT5720 completely blocked the enhancement of LTP produced by the treatment of 7-d nicotine and cocaine (KT5720+nicotine+cocaine, $110 \pm 4 \%$, $n=5$; nicotine +cocaine, $143 \pm 5 \%, n=$ $6, P<0.01$ ) (Fig. 3F). These results indicate that the regulation of the D1/D5 receptors on the priming effect of nicotine may be mediated through activation of the PKA signaling pathway.

\section{Histone acetylation mediates the priming effect in the DG}

Histone acetylation plays an important role in learning and memory (Alarcon et al. 2004; Vecsey et al. 2007) as well as in drug addiction (Levine et al. 2005, 2011; Renthal and Nestler 2008; Wang et al. 2010). Our previous work has found that the administration of the HDAC inhibitor SAHA (suberoylanilide hydroxamic acid) can simulate the priming effect of nicotine on cocaine in the expression of LTP in the NAc and amygdala (Levine et al. 2011; Huang et al. 2013). Does histone deacetylation play any role in the priming effect of nicotine on 
A 7 -d SKF 83566 \& nicotine+cocaine

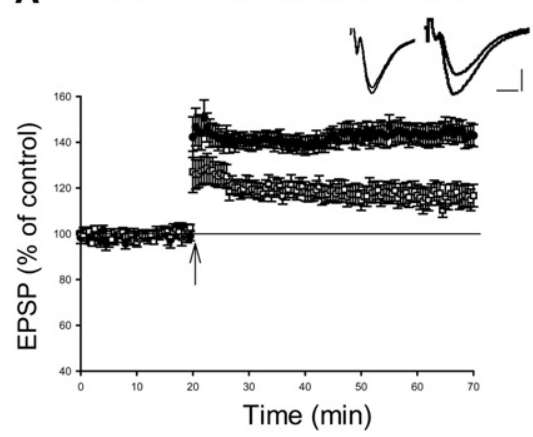

C 7-d SKF 38393 \&nicotine+cocaine

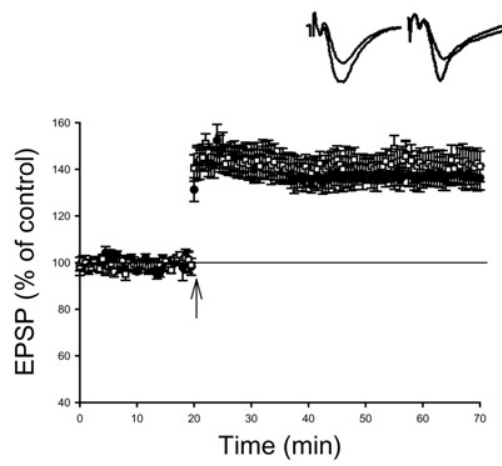

E $\quad$ 1-d SKF38393

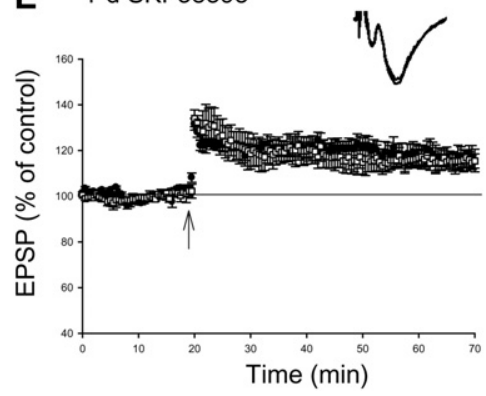

B $\quad$ 7-d SKF 83566

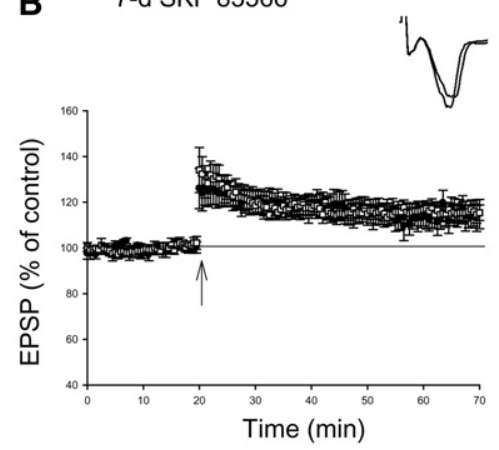

D 1-d SKF38393\&nicotine+cocaine
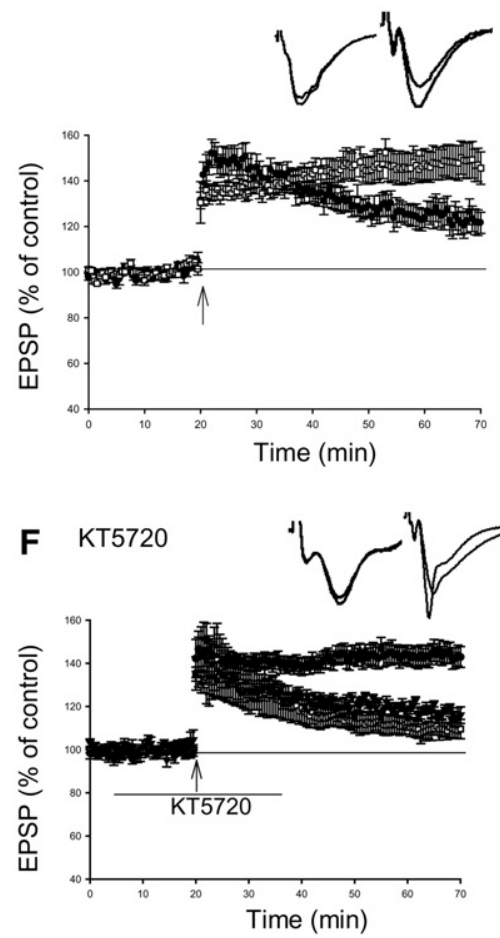

Figure 3. The priming effect on LTP is mediated by D1/D5 receptors. ( $A$ ) Oral administration of the D1 receptor antagonist SKF 83566 together with nicotine for $7 \mathrm{~d}$ blocked the enhancement of LTP in the DG. (Open squares) 7-d SKF 83566+ nicotine+cocaine, (closed circles) 7-day nicotine+cocaine. (B) SKF 83566 alone did not alter LTP. (Closed circles) 7-d SKF 83566, (open squares) control. (C) Oral administration of the D1 agonist SKF 38393 together with nicotine prior to cocaine did not further enhance the priming effect on LTP induced by 7-d nicotine/cocaine. (Open squares) 7-d SKF $38393+$ nicotine + cocaine, (closed circles) 7-d nicotine+cocaine. (D) Oral administration of the D1 agonist SKF 38393 significantly enhanced LTP induced by 1-d nicotine exposure and cocaine. (Open squares) SKF 38393 +1-d nicotine+cocaine, (closed circles) 1-d nicotine + cocaine. (E) Oral administration of the D1 agonist SKF 38393 alone did not alter LTP. (Closed circles) SKF 38393, (open squares) control. $(F)$ The protein kinase A (PKA) inhibitor KT5720 blocked the enhancement of LTP induced by 7-d nicotine and cocaine. (Open squares) KT5720+7-d nicotine+cocaine, (closed triangle) KT5720, (closed circles) 7-d nicotine+cocaine.

cocaine in the DG? To address this question we first tested the effect of the HDAC inhibitor SAHA. A single injection of SAHA in vivo $(50 \mathrm{mg} / \mathrm{kg}$, intraperitoneal injection [i.p.], 10-20 min before the sacrifice of mice) did not significantly alter DG-LTP induced by a single tetanus $(1 \times 100 \mathrm{~Hz})(\mathrm{SAHA}, 115 \pm 7 \%, n=6$; control, $114 \pm 6 \%, n=6, P>0.05$ ) (Fig. 4A). However, when the injection of SAHA was followed by an injection of cocaine (SAHA 10 min prior to cocaine), the same tetanus now elicited a greater LTP $(142 \pm 11 \%, n=10)$, which was significantly different from LTP in mice treated with cocaine alone (112 $\pm 3 \%, n=6, P<0.01)$ (Fig. 4B). This result indicates that the HDAC inhibitor SAHA can mimic the priming effect of nicotine on cocaine. Similar to nicotine, the priming effect of SAHA is unidirectional. When SAHA was injected after the injection of cocaine (cocaine 10 min prior to SAHA), no facilitation of LTP was observed $(116 \pm 5 \%, n=6, P>0.05)$ (Fig. 4C). A histogram comparing the effects of SAHA, cocaine by itself, and the combination of SAHA and cocaine is shown in Figure 4D.

Previously, we found that chronic histone treatment $(7 \mathrm{~d}, 10 \mathrm{ng} / \mathrm{mL})$ induced a global hyperacetylation of histone in the striatum (Levine et al. 2011). To further examine the priming effect of nicotine on the DG, we looked at the acetylation levels of histone $\mathrm{H} 3$ following $7 \mathrm{~d}$ of nicotine and cocaine exposure. We found that, similar to its effect in the striatum, in the DG nicotine increases the acetylation of histone $\mathrm{H} 3$ at Lysine 9 (AcH3, $2.37 \pm 24 \%, P=0.011$, $n=5$ ), while cocaine does not induce a significant increase of histone acetylation (AcH3, $1.10 \pm 5 \%, P=0.9, n=5)$ (Fig. 4E).

CREB-binding protein CBP is a histone acetyl transferase (HAT). CBP haploinsufficient $(\mathrm{CBP}+/-)$ mice carry only one functional CBP allele. In these mice, the basal recruitment of histone (H4) acetylation at the Fos B promoter is significantly decreased compared with wild-type (WT) mice (Alarcon et al. 2004; Levine et al. 2005). To further study the role of HDAC in the priming effect of nicotine, we examined the priming effect in the DG of $\mathrm{CBP}+/-$ mice. As in the hippocampal CA1 region (Alarcon et al. 2004), there were no differences in the input-output curves (Fig. 5A) and in LTP induced by single tetanus $(1 \times 100$ $\mathrm{Hz}$ ) between WT and $\mathrm{CBP}+/-$ mice (WT, $115 \pm 7 \%, n=6$; KO, $116 \pm 8 \%$, $n=6, P>0.05$ ) (Fig. 5B). A single injection of cocaine (WT, $120 \pm 3 \%, n=5$; KO, $115 \pm 5 \%, n=5, P>0.05$ ) (Fig. 5C), or 7-d exposure to nicotine (WT, $117 \pm$ $3 \%, n=6$; KO, $113 \pm 4 \%, n=6$ ) (Fig. 5D) did not alter LTP either in WT or $\mathrm{CBP}+/-$ mice. However, when a cocaine injection was primed by 7-d nicotine exposure, a significant enhancement of LTP was obtained in the WT mice (nicotine+cocaine, $141 \pm 3 \%$, $n=8, P<0.01$ ), but not in the $\mathrm{CBP}+/-$ mice (nicotine + cocaine, $120 \pm 3 \%, n=12, P<0.05$ ) (Fig. 5E). Figure 5F displays a histogram showing the effects of nicotine, cocaine, and nicotine plus cocaine on DG-LTP in WT and CBP+/ - mice. These results indicate that the priming effect of nicotine on cocaine is blunted in $\mathrm{CBP}+/-$ mice, which are essentially in a chronic hypoacetylated state, and provide genetic evidence that the priming effect of nicotine in the DG is mediated through histone deacetylation. 
A SAHA only
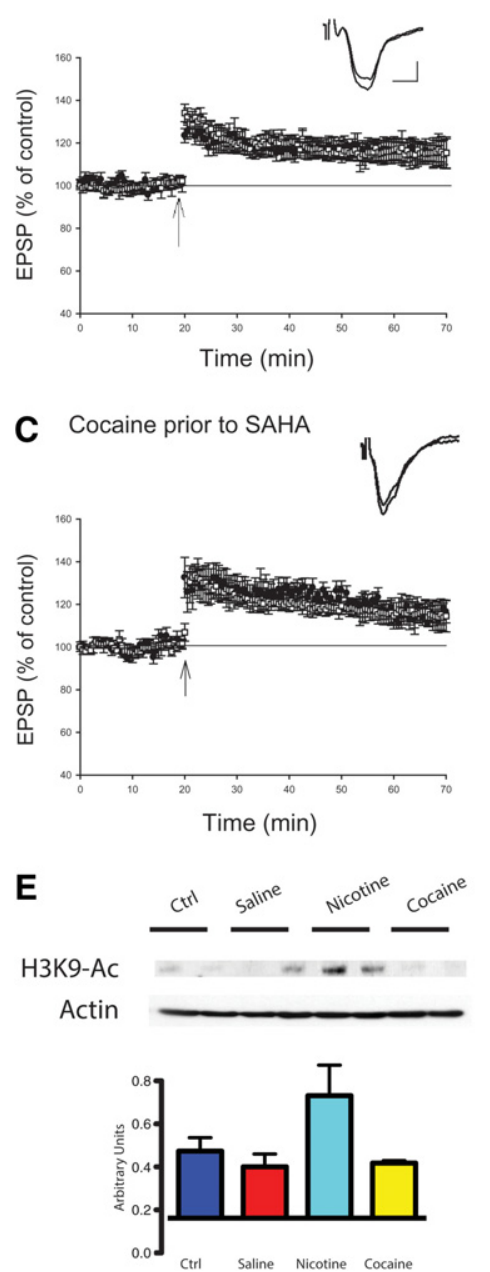

B SAHA prior to Cocaine

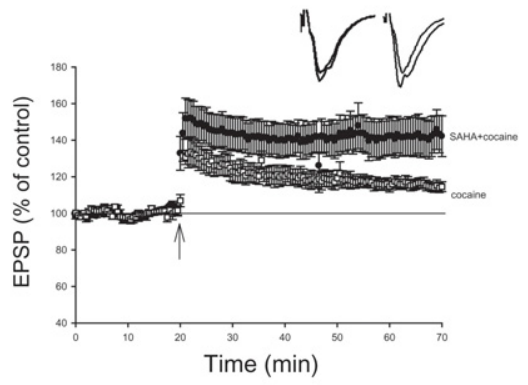

D

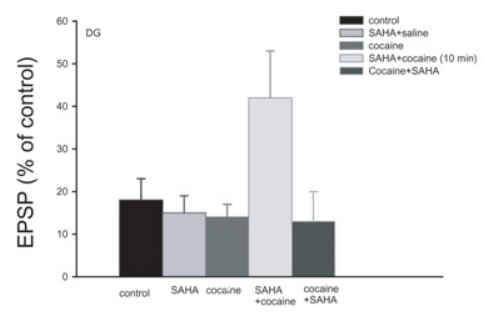

et al. 2006; Gozen et al. 2013). Moreover, coadministration of nicotine and D1/D5 receptor agonists seems to produce a higher level of activation of the D1/D5 receptors and may consequently enhance PKA and PKA-mediated phosphorylation of the transcription factor cAMP response element binding protein (CREB). Second, we find that activation of D1/D5 receptors enhances the level of $\Delta$ FosB (Doucet et al. 1996; Muller and Unterwald 2005), which is a critical molecular switch for drug addiction (Nestler 2004). Importantly, the administration of nicotine prior to cocaine produces a unidirectional enhancement of $\Delta$ FosB. The reverse order has no effect (Levine et al. 2011). $\Delta$ FosB controls the unidirectional priming effect of nicotine on cocaine via mediation of histone acetylation (Levine et al. 2005, 2011).When nicotine was coadministered with the D1/D5 receptor agonists, nicotine and the subsequent administration of cocaine produced a higher level of activation of the D1/D5 receptors. This enhanced PKA-mediated phosphorylation of the transcription factor CREB and the expression of $\Delta$ FosB and other immediate-early genes, such as Fos and Jun, lead to greater LTP. By contrast, when nicotine was coadministered with the D1/D5 receptor antagonists, the effect of nicotine on the activation of D1/ D5 receptors and the increase of $\Delta$ FosB was blocked, thereby preventing the priming effect of nicotine on the induction of LTP. Finally, our data suggest that the effect of D1/D5 receptors on the priming effect in the DG may be mediated directly through the regulation of HDAC. Genetic inactivation of dopamine D1 but not D2 receptors inhibits histone acetylation (Darmopil et al. 2009). When a D1 receptor agonist is given together with the HDAC inhibitor, the combination enhances cocaine-in-

\section{Discussion}

The DG in the hippocampus receives dopaminergic innervation from the ventral tegmental area (VTA) and the DG contains dopamine D1/D5 receptors (Fremeau et al. 1991; Meador-Woodruff et al. 1992; Gangarossa et al. 2012). The alteration of the functioning of these receptors may be related to the induction of drug-induced memory (Tanaka et al. 2011). Although many studies have explored the role of the dopaminergic system on the effects of nicotine by itself (Damaj and Martin 1993; Mansvelder and McGehee 2002; Kauer and Malenka 2007; Tang and Dani 2009), the role of the dopaminergic system in the priming effect of nicotine on cocaine has not been previously investigated. Here we have provided evidence showing that dopamine receptors play an important role in the priming effect of nicotine.

We first asked: What are the mechanisms underlying the modulation of D1/D5 receptors in the priming effect? We find that the administration of nicotine activates D1/D5 receptors (O'Neil et al. 1991; Shoaib 1998; Hamada et al. 2004; Hyman duced locomotor response and conditioned place preference (Schroeder et al. 2008). The nicotine-induced activation of D1/ D5 receptors may lead to phosphorylation of CREB (Nestler 2004; Hyman et al. 2006), which recruits the CREB-binding protein (CBP), a histone acetyl transferase that acetylates histones and consequently influences the transcription of genes and the modification of synapses (Kandel 2001; Guan et al. 2002; Alarcon et al. 2004; Levine et al. 2005). In addition to the D1/D5 receptors, exposure to nicotine activates dopamine D2 receptors (Hamada et al. 2004; Novak et al. 2010), which may also be involved in the mediation of the priming effect of nicotine on cocaine. However, since D2 receptors are negatively coupled with the cAMP signaling pathway (Beaulieu and Gainetdinov 2011), the involvement of D2 receptors may mediate the nicotine effect through a signaling pathway that is different from that of the D1 receptors and unrelated to HDAC (Hamada et al. 2004; Grieder et al. 2011).

Histone acetylation and deacetylation seem to play a critical role in drug addiction (Levine et al. 2005, 2011; Renthal and 
A
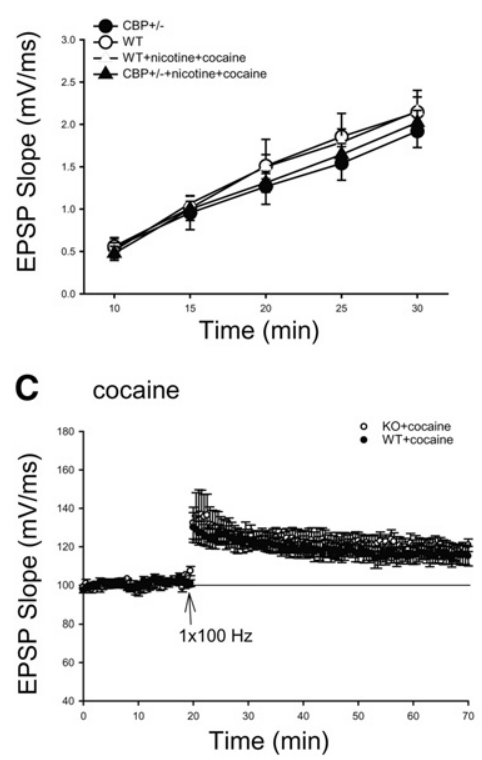

E 7-d nicotine+cocaine

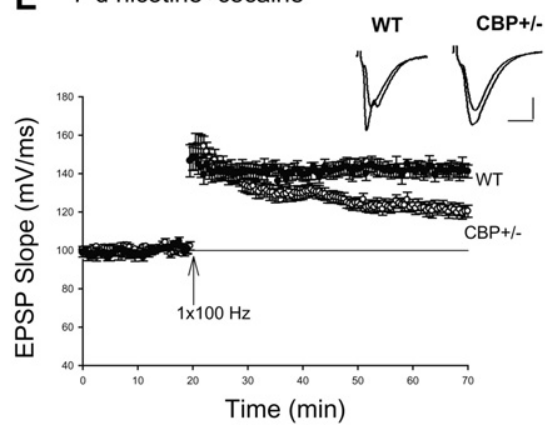

B
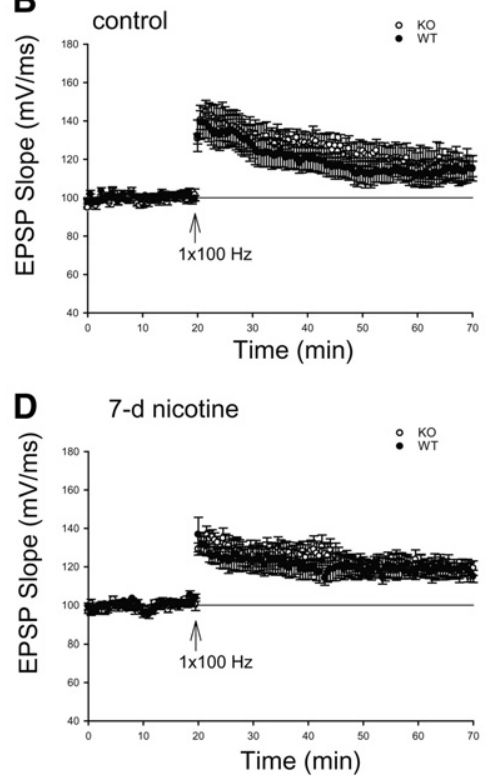

$\mathbf{F}$

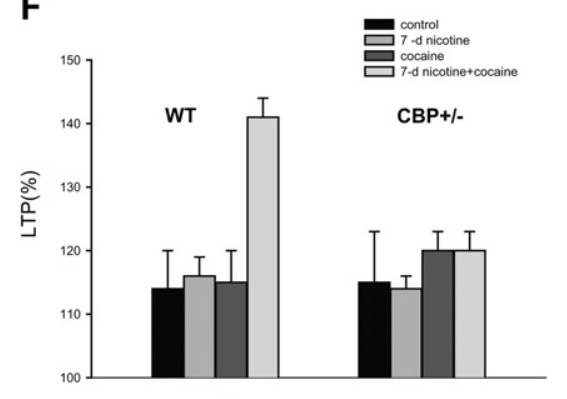

Figure 5. The priming effect is impaired in $\mathrm{CBP}+/-$ mice. $(A)$ There are no significant differences in the input-output curves between WT and CBP $+/-$ mice. $(B)$ LTP induced by a single train of tetanus $(1 \times 100 \mathrm{~Hz})$ is normal in CBP $+/-$ mice. (C) A single injection of cocaine did not alter LTP either in WT or CBP+ / - mice. (D) Seven days' exposure of nicotine did not alter LTP either in WT or CBP+/ - mice. (E) The pretreatment with nicotine (7-d) prior to cocaine produced a significant enhancement of LTP in the WT but not the CBP $+/-$ mice. (Open circles) 7-d nicotine+cocaine in CBP $+/-$ mice, (closed circles) 7-d nicotine + cocaine in WT mice. ( $F$ ) A histogram comparing the effect of nicotine, cocaine, and nicotine plus cocaine on LTP in WT and CBP $+/-$ mice. Top panel shows the representative field EPSPs in WT and CBP+/ - mice. Calibration: $10 \mathrm{msec}, 1 \mathrm{mV}$.

Nestler 2008). We here provide further pharmacological and genetic evidence showing that the priming of LTP in the DG is also mediated through histone acetylation. The HDAC inhibitor SAHA mimics the priming effect of nicotine. In addition, nicotine priming of cocaine produces an enhancement of DG-LTP induced by a single tetanus in WT mice, but does not do so in CBP+/mice, which are essentially in a chronic hypoacetylated state. This may be because the association between nicotine and cocaine achieves a sufficient enhancement of histone acetylation in the WT mice that is required for switching a weak form of LTP to a strong form. By contrast, the enhancement of histone acetylation produced by the association of nicotine and cocaine appears to be insufficient in $\mathrm{CBP}+/-$ mice. As a result, nicotine and cocaine may be unable to enhance the amplitude of LTP in these mice. This result is consistent with our earlier studies, in which we found that $\mathrm{CBP}+/-$ mice have deficits in producing a strong and stable form of LTP in the hippocampal CA1 region (Alarcon et al. 2004).

The present study therefore provides new evidence supporting the idea that, in the dentate gyrus, as in the striatum and in the amygdala, the priming effect of nicotine on cocaine may be mediated, at least partially, by the inhibition of histone deacetylation and the recruitment of CBP-mediated gene transcription.

\section{Materials and Methods}

Male C57BL6/J mice (6- to 9-wk-old) (Jackson Laboratories, Bar Harbor, ME) were kept in clear plastic cages $(29.2 \times$ $19 \times 12.7 \mathrm{~cm}, \mathrm{~N} 10$ cage, Ancare) in groups of five with ad libitum food (Prolab IsoPro RMH3000, PMI Nutrition International LLC) and water (autoclaved tap water). Mice were kept at a 12-h day-night cycle.

The generation of $\mathrm{CBP}+/$ - mice was described previously (Tanaka et al. 1997; Alarcon et al. 2004). The WT mice used as control group were litter mates of the $\mathrm{CBP}+$ / - mice. Mice were maintained and bred under standard conditions, consistent with National Institutes of Health guidelines and approved by the Institutional Animal Care and Use Committee of Columbia University.

After receiving different drug treatments, mice were quickly decapitated and placed in ice-cold ACSF (artificial cerebrospinal fluid). The hippocampus was removed and transverse slices of brain $(400 \mu \mathrm{M})$ were cut and transferred to an interface chamber (Harvard Apparatus). Slices were half-submerged and constantly perfused with ACSF at a rate of $2 \mathrm{~mL} / \mathrm{min}$ and bubbled with 95\% $\mathrm{O}_{2}$ and $5 \% \mathrm{CO}_{2}$. The composition of ACSF was as follows (in $\mathrm{mM}$ ): $124 \mathrm{NaCl}, 1.2$ $\mathrm{MgSO}_{4}, 4 \mathrm{KCl}, 1.0 \mathrm{NaH}_{2} \mathrm{PO}_{4}, 2 \mathrm{CaCl}_{2}$, $26 \mathrm{NaHCO}_{3}$, and 10 D-glucose. All experiments were performed in the intact GABAergic inhibition (without picrotoxin). The temperature of the slices was maintained at $28^{\circ} \mathrm{C}$. Experiments were started $2.5 \mathrm{~h}$ after slices were dissected.

Extracellular recordings were made using ACSF-filled glass electrodes (1-3 $\mathrm{M} \Omega)$. Stimuli were delivered at a rate of every $30 \mathrm{sec}(0.033 \mathrm{~Hz}, 0.05 \mathrm{msec}$ pulse duration) through concentric bipolar stainless-steel electrodes ( $25 \mu \mathrm{M}$ wire diameter, CBBRC75, FHC). The stimulating electrodes were placed in the middle of molecular layers of the dentate gyrus (DG), which contained fibers from the perforant pathway. The recording electrodes were placed in the middle molecular layer of the DG (Fig. 1A). Medial pathway responses were confirmed by the depression of fEPSP elicited by paired-pulse stimulation (Nguyen and Kandel 1996). The stimulation intensity was adjusted to evoke the field potential that was $\sim 50 \%$ of maximal amplitude. Baseline values were acquired over a period of $20 \mathrm{~min}$ before giving the LTP inducing stimulation. LTP was elicited by a single train of tetanus $(1 \times 100 \mathrm{~Hz}$, $1 \mathrm{sec}$, and $0.1 \mathrm{msec}$ pulse duration). Changes in synaptic strength were expressed relative to the normalized baseline (mean \pm SEM). Statistical comparisons were performed using Student's $t$-test.

Nicotine hydrogen tartrate salt (Sigma) was dissolved in drinking water $(10 \mu \mathrm{g} / \mathrm{mL})$ and administered continuously in the drinking water for $1 \mathrm{~d}$, or $7 \mathrm{~d}$ prior to the experiment day. Cocaine hydrochloride (Sigma) was dissolved in sterile saline and administered by intraperitoneal injection (i.p. $30 \mathrm{mg} / \mathrm{kg}$ ) $10 \mathrm{~min}$ before mice were sacrificed. Suberoylanilide hydroxamic acid (SAHA, $50 \mathrm{mg} / \mathrm{kg}$ ) was dissolved in DMSO and administered 
by i.p. 10 min prior to the injection of cocaine or, conversely, 10 min after the injection of cocaine (in this experiment cocaine was injected $20 \mathrm{~min}$ before the sacrifice of mice). For the oral administration, the D1/D5 antagonist SKF $83566(20 \mu \mathrm{g} / \mathrm{mL}$, Tocris) and agonist SKF $38393(10 \mu \mathrm{g} / \mathrm{mL}$, Sigma) were dissolved in the drinking water. For the bath application of KT5720 onto brain slices, stock solutions (in DMSO, Sigma) were prepared and were diluted 1000 times when applied into the perfusion solution.

To measure acetylation, mice were treated with saline, nicotine alone, and cocaine alone for $7 \mathrm{~d}$, then the brain was removed and the dentate gyrus of hippocampus was dissected. Striata were dissected in PBS on ice and homogenized in $0.25 \%$ Triton X-100, $0.5 \%$ Nonidet P-40, 10 mM EDTA, 0.5 mM EGTA, 10 mM Tris. $\mathrm{HCl}$ ( $\mathrm{pH} 8.0)$, and $1 \mathrm{mM}$ PMSF. Thirty micrograms of protein were used for detection of acetylated histone H3 and separated by SDS/15\% PAGE. After electrophoresis, and western blotting, the membrane was probed with antibody specific for acetylated Histone $\mathrm{H} 3$ at Lysine 9 (Millipore) overnight at $4^{\circ} \mathrm{C}$. Blot was incubated with an anti-rabbit IgG-HRP as secondary antibody (1:5000, Sigma) for $1 \mathrm{~h}$ at room temperature, and detected by using ECL (Amersham Pharmacia). To verify the accuracy of sample loading, the blot was reprobed with a monoclonal antibody to actin (1:10,000, Sigma). Acetylated H3 bands were measured at 17 $\mathrm{kDa}$. Relative optical density readings for the acetylated Histone $\mathrm{H} 3$ and actin bands were determined by comparing $\mathrm{H} 3$ and actin densities.

\section{Acknowledgments}

We thank R. Breslow for kindly providing the Suberoylanilide hydroxamic acid (SAHA). This work was supported by the Howard Hughes Medical Institute (E.R.K.), NIH grants 5 R01 DA024001 (E.R.K., D.B.K., A.L.; multiple principal investigators) and K 5 DA00081 (D.B.K.), the New York State Psychiatric Institute (Y.-Y.H., A.L.), and the Italian Academy for Advanced Studies in America of Columbia University (B.D., L.C.).

\section{References}

Aimons JB, Deng W, Gage FH. 2010. Adult neurogenesis: Integrating theories and separating functions. Trends Cogn Sci 14: 325-327.

Alarcon JM, Malleret G, Touzani K, Vronskays S, Ishil S, Kandel ER, Barco A. 2004. Chromatin acetylation, memory, and LTP are impaired in $\mathrm{CBP}+/-$ mice: A model for the cognitive deficit in Rubinstein-Taybi syndrome and its amelioration. Neuron 42: 947-958.

Aleisa AM, Helal G, Alhaider IA, Alzoubi KH, Srivareerat M, Tran TT, Al-Rejaie SS, Alkadhi KA. 2011. Acute nicotine treatment prevents REM sleep deprivation-induced learning and memory impairment in rat. Hippocampus 21: 899-909.

Beaulieu J-M, Gainetdinov RR. 2011. The physiology, signaling and pharmacology of dopamine receptor. Pharmacol Rev 63: 182-217.

Braun A, Fabbrini G, Mouradian MM, Serrati C, Barone P, Chase TN. 1987. Selective D-1 dopamine receptor agonist treatment of Parkinson's disease. I Neural Transm 68: 41-50.

Canales JJ. 2007. Adult neurogenesis and the memories of drug addiction. Eur Arch Psychiatry Clin Neurosci 257: 261-270.

Canales JJ. 2010. Comparative neuroscience of stimulant-induced memory dysfunction: Role for neurogenesis in the adult hippocampus. Behav Pharmacol 21: 379-393.

Christie BR, Cameron HA. 2006. Neurogenesis in the adult hippocampus. Hippocampus 16: 199-207

Collins SL, Montano R, Izenwasser S. 2004. Nicotine treatment produces persistent increase in amphetamine-stimulated locomotor activity in periadolescent male but not female or adult male rats. Dev Brain Res 153: $175-187$.

Curran BP, Connor JJ. 2003. The inhibition of long-term potentiation in the rat dentate gyrus by pro-inflammatory cytokines is attenuated in the presence of nicotine. Neurosci Lett 344: 103-106.

Damaj MJ, Martin BR. 1993. Is the dopaminergic system involved in the central effects of nicotine in mice? Psychopharmacology 111: $106-108$.

Darmopil S, Martin AB, Diego IRD, Ares S, Moratalla RM. 2009. Genetic inactivation of dopamine D1 but not D2 receptor inhibits L-DOPAinduced dyskinesia and histone activation. Biol Psychiatry 66: 603-613.
Desai RI, Terry P. 2003. Evidence of cross-tolerance between behavioral effects of nicotine and cocaine in mice. Psychopharmacology (Berl) 166: $111-119$.

Doucet JP, Nakabeppu Y, Bedard PJ, Hope BT, Nestler EJ, Jasmin BJ, Chen JS, Ladarola MJ, St-jean M, Wigle N, et al. 1996. Chronic alternations in dopaminergic neurotransmission produce a persistent alavatin of $\Delta$ FosB-like protein(s) in both the rodent and primate striatum. Eur J Neurosci 2: 365-381.

Eisch AJ, Harburg GC. 2006. Opiates, psychostimulants, and adult hippocampal neurogenesis: Insights for addiction and stem cell biology. Hippocampus 16: 271-286.

Fole A, Gonzalez-Martin G, Huarte G, Alguacil LF, Ambrosio E, Olmo ND. 2011. Effects of chronic cocaine administration on spatial learning and hippocampal spine in two genetically different strains of rats. Neurobiol Learn Mem 95: 491-497.

Fremeau RT Jr, Duncan GE, Fornaretto M-G, Dearry A, Gingrich JA, Breese GR, Caron MG. 1991. Localization of D1 dopamine receptor mRNA in brain supports a role in cognitive, affective, and neuroendocrine aspects of dopaminergic neurotransmission. Proc Natl Acad Sci 88: 3772-3776.

Gangarossa G, Longueville S, Bundel DD, Perroy J, Herve D, Girault J-A, Valjent E. 2012. Characterization of dopamine D1 and D2 receptor-expressing neurons in the mouse hippocampus. Hippocampus 22: 2199-2207.

Gozen O, Balkan B, Yildirim E, Koylu EO, Pogun S. 2013. The epigenetic effect of nicotine on dopamine D1 receptor expression in rat prefrontal cortex. Synapse 67: 545-552.

Grieder TE, George O, Tan H, George SR, Foll BL, Leviolette SR, Kooy DVD. 2011. Phasic D1 and tonic D2 dopamine receptor signaling double dissociate the motivational effect of acute nicotine and chronic nicotine withdrawal. PNAS 100: 3101-3108.

Guan Z, Giustetto M, Lomvardas S, Kim J-H, Miniaci MC, Schwartz JH, Thanos D, Kandel ER. 2002. Integration of long-term-memory-related synaptic plasticity involves bidirectional regulation of gene expression and chromatin structure. Cell 111: 483-493.

Hamada M, Higashi H, Naim AC, Greengard P, Nishi A. 2004. Differential regulation of dopamine D1 and D2 signaling by nicotine in neostriatal neurons. J Neurochem 90: 1094-1103.

Hernandez-Rabaza V, Hontecillas-Prieto L, Velazquez-Sanchez C, Ferragud A, Perez-Villaba A, Arcusa A, Barcia JA, Trejo JL, Canales JJ. 2008. The hippocampal dentate gyrus is essential for generating contextual memories of fear and drug-induced reward. Neurobiol Learn Mem 90: 553-559.

Huang Y-Y, Kandel DB, Kandel ER, Levine A. 2013. Nicotine primes the effect of cocaine on the induction of LTP in the amygdala. Neuropharmacology 74: 126-134.

Hyman SC, Malenka RC, Nestler E. 2006. Neural mechanisms of addiction: The role of reward-related learning and memory. Annu Rev Neurosci 29: 565-598.

Iniguez SD, Charntikov S, Baella SA, Herbert MS, Bolanos-Guzman CA, Grawford CA. 2012. Post training cocaine exposure facilitates spatial memory consolidation in $c 57 \mathrm{BL} / 6$ mice. Hippocampus 22: 802-813.

Kandel DB. 1975. Stages in adolescent involvement in drug use. Science 190: $912-914$.

Kandel ER. 2001. The molecular biology of memory storage: A dialogue between genes and synapses. Science 294: 1030-1038.

Kandel DB, ed. 2002. Stages and pathways of drug involvement: examining the gateway hypothesis, pp. 3-5. Cambridge University Press, Cambridge, UK.

Kauer JA, Malenka RC. 2007. Synaptic plasticity and addiction. Nat Rev Neurosci 8: 845-858.

Kenney JW, Gould TJ. 2008. Modulation of hippocampus-dependent learning and synaptic plasticity by nicotine. Mol Neurobiol 38: $101-121$.

Klein LC. 2001. Effects of adolescent nicotine exposure on opioid consumption and neuroendocrine responses in adult male and female rats. Exp Clin Psychopharmacol 9: 251-261.

Levine A, Guan Z, Barco A, Xu S, Kandel ER, Schwartz JH. 2005. CREB-binding protein control response to cocaine by acetylating histones at the fos B promoter in the mouse striatum. Proc Natl Acad Sci 42: $947-959$.

Levine A, Huang YY, Drisaldi B, Griffin EA Jr, Pollak DD, Xu S, Yin D, Schafran C, Kandel DB, Kandel ER. 2011. Molecular mechanism for a gateway drug: Epigenetic changes initiated by nicotine prime gene expression by cocaine. Sci Transl Med 3: 107

Mansvelder HD, McGehee DS. 2002. Cellular and synaptic mechanisms of nicotine addiction. J Neurobiol 53: 606-617.

Matsuyama S, Matsumoto A, Enomoto T, Nishizaki T. 2000. Activation of nicotine acetylcholine receptors induces long-term potentiation in vivo in the intact mouse dentate gyrus. Eur J Neurosci 12: $3741-3747$. 
McMillen BA, Davis BJ, Williams HL, Soderstrom K. 2005. Periadolescent nicotine exposure causes heterologous sensitization to cocaine reinforcement. Eur J Pharmacol 1509: 161-164.

McQuown SC, Dao JM, Belluzzi JD, Leslie FM. 2009. Age-dependent effects of low-dose nicotine treatment on cocaine-induced behavioral plasticity in rats. Psychopharmacology 207: 143-152.

Meador-Woodruff JH, Mansour A, Grandy DK, Damask SP, Civeli O, Wantson SJ Jr. 1992. Distribution of D5 dopamine receptor mRNA in rat brain. Neurosci Lett 145: 209-212.

Mello NK, Newman JL. 2011. Discriminative and reinforcing stimulus effects of nicotine, cocaine, and cocaine + nicotine combinations in rhesus monkeys. Exp Clin Psychopharmacol 19: 203-214.

Meyers RA, Zavala AR, Speer CM, Neisewander JL. 2006. Dorsal hippocampus inhibition disrupts acquisition and expression, but not consolidation, of cocaine conditioned place preference. Behav Neurosci 120: $401-412$.

Muller DL, Unterwald EM. 2005. D1 dopamine receptors modulate FosB induction in striatum after intermittent morphine administration. $J$ Pharmacol Exp Ther 314: 148-154.

Nakagome K, Immamura M, Okada H, Kawahata K, Inoue T, Hashimoto K, Harada K, Harada H, Higashi T, Takagi R, et al. 2011. Dopamine D1-like receptor antagonist attenuates Th17-mediated immune response and ovalbumin antigen-induced neutrophilic airway inflammation. J Immunol 186: 5957-5982.

Nestler EJ. 2004. Molecular mechanisms of drug addiction. Neuropharmacology 47: 24-32.

Nguyen PV, Kandel ER. 1996. A macromolecular synthesis-dependent late phase of long-term potentiation requiring cAMP in the medial perforant pathway of rat hippocampal slices. J Neurosci 16: 3189-3198.

Noona MA, Bulin SE, Fuller DC, Eisch AJ. 2010. Reduction of adult hippocampal neurogenesis confers vulnerability in an animal model of cocaine addiction. J Neurosci 30: 304-375.

Novak G, Seeman P, Foll BL. 2010. Exposure to nicotine produces an increase in dopamine D2 receptors: A possible mechanism for dopamine hypersensitivity. Int J Neurosci 120: 691-697.

O'Neil MF, Dorish CT, Iversen SD. 1991. Evidence for and involvement of D1 and D2 dopamine receptors in mediating nicotine-induced hyperactivity in rats. Psychopharmacology 104: 343-350.

Perez MF, Gabach LA, Almiron RS, Carini VP, De-Barioglio SR, Ramirez OA. 2010. Different chronic cocaine administration protocols induce changes on dentate gyrus plasticity and hippocampal dependent behavior. Synapse 64: 742-753.

Renthal W, Nestler EJ. 2008. Histone acetylation in drug addiction. Semin Cell Dev Biol 20: 339-387.
Sawada S, Yamamoto C, Ohno-Shosaku T. 1994. Long-term potentiation and depression in the dentate gyrus, and effects of nicotine. Neurosci Res 4: $323-329$.

Scerri C, Stewart C, Breen KC, Balfour DK. 2006. The effects of chronic nicotine on spatial learning and bromodeoxyuridine incorporation into the dentate gurus of the rat. Psychopharmacology 184: 540-546.

Schroeder FA, Penta KL, Matevossian A, Jones SR, Konradi C, Tapper AR, Akbarian S. 2008. Drug-induced activation of dopamine D1 receptor signaling and inhibition of class I/II histone deacetylase induces chromatin remodeling in reward circuitry and modulates cocaine-related behaviors. Neuropsychopharmacology 33: 2981-2992.

Shoaib M. 1998. Is dopamine important in nicotine dependence? J Physiol Paris 92: 229-233.

Tanaka Y, Naruse I, Maekawa H, Shiroishi T, Ishii S. 1997. Abnormal skeletal patterning in embryos lacking a single cbp alle: A partial similarity with Rubinstein-Taybi syndrome. Proc Natl Acad Sci 94: 10215-10220.

Tanaka T, Kai N, Kobayashi K, Takano Y, Hironaka N. 2011. Up-regulation of dopamine D1 receptor in the hippocampus after establishment of conditioned place preference by cocaine. Neuropharmacology 61: $842-848$.

Tang J, Dani JA. 2009. Dopamine enables in vivo synaptic plasticity associated with the addictive drug nicotine. Neuron 63: 673-682.

Vecsey CG, Hawk JD, Lattal KM, Stein JM, Fabian SA, Attner MA, Cabrera SM, McDonough CB, Brindle PK, Abel T, et al. 2007. Histone deacetylase inhibitors enhance memory and synaptic plasticity via CREB:CBP-dependent transcriptional activation. J Neurosci 27: $6128-6140$

Wang L, Lv Z, Hu Z, Sheng J, Hui B, Sun J, Ma L. 2010. Chronic cocaine-induced $\mathrm{H} 3$ acetylation and transcriptional activation of CaMKII $\alpha$ in the nucleus accumbens is critical for motivation for drug reinforcement. Neuropsychopharmacology 35: 913-918.

Welsby P, Rowan MJ, Anwyl R. 2006. Nicotine receptor-mediated enhancement of long-term potentiation involves activation of metabotropic glutamate receptors and ryanodine-sensitive calcium stores in the dentate gurus. Eur J Neurosci 24: 3109-3118.

Welsby PJ, Rowan M, Anwyl R. 2009. Intracellular mechanisms underlying the nicotine enhancement of LTP in the rat dentate gyrus. Eur J Neurosci 29: $65-75$.

Yamaguchi K. 1984. Patterns of drug use from adolescence to young adulthood: II. Sequences of progression. Am J Public Health 74: $668-672$.

Received July 2, 2013; accepted in revised form December 9, 2013 


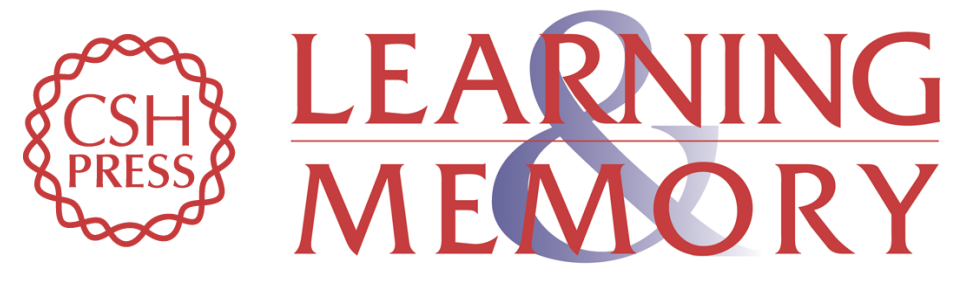

\section{D1/D5 receptors and histone deacetylation mediate the Gateway Effect of LTP in hippocampal dentate gyrus}

Yan-You Huang, Amir Levine, Denise B. Kandel, et al.

Learn. Mem. 2014, 21:

Access the most recent version at doi:10.1101/Im.032292.113

References This article cites 61 articles, 9 of which can be accessed free at: http://learnmem.cshlp.org/content/21/3/153.full.html\#ref-list-1

Creative This article, published in Learning \& Memory, is available under a Creative Commons Commons License http://creativecommons.org/licenses/by-nc/3.0/.

Email Alerting Receive free email alerts when new articles cite this article - sign up in the box at the Service top right corner of the article or click here. 